\title{
KINETOGRAFIA: INTERPRETAÇÃO DOS KINETOGRAMAS EM UM CASO DE ATETOSE UNILATERAL
}

\author{
MiLTON B. MOREIRA *
}

Kinetograma é o registro gráfico dos movimentos manuais efetuados pelo paciente ao tentar executar um diagrama linear, prèviamente convencionado, sôbre um modêlo impresso em fôlha de papel fixada a prancheta que pode ser deslocada do plano horizontal para o vertical 4 .

O protocolo do teste é constituído por lineogramas retilíneos em direção sagital, transversal e vertical, os quais devem ser realizados no duplo sentido, em seqüência ininterrupta. Também são feitas circunferências superpostas, no sentido destrógiro com a mão direita e levógiro com a mão esquerda, no plano vertical. Outra prova consiste em efetuar pequenas circunferências conectadas e alinhadas em filas ou cadeias longitudinais, parassagitais e paralelas, em ordenação sucessiva, no sentido egocífugo ou egocípeto, nos planos horizontal e vertical. Integram o teste as confecçóes de outras formas geométricas, compostas de elementos retilíneos, constituindo ziguezagues, degraus ascendentes e descendentes, paralelas equimétricas e equidistantes executadas no sentido egocífugo ou egocípeto dentro de um retângulo. Figura em forma de $U$, nos planos vertical e horizontal; também serve como guia ou modêlo para a kinetografia 1,3, 4 .

Os kinetogramas são feitos a lápis pelo paciente, com cada mão isoladamente. Sòmente os ziguezagues paralelos e parassagitais são feitos com as duas mãos, com um lápis em cada, sem se tocarem, em movimentos simultâneos, simétricos e sinérgicos, no plano horizontal ${ }^{3}$.

Durante a realização do teste o paciente deve manter o lápis perpendicular ao plano em que é realizado o traçado (a mão livre). Inicialmente o executa com o concurso visual, procurando cobrir a traço de lápis exatamente a linha impressa que lhe serve de modêlo (três vêzes). Prossegue sem vê-la (10 vêzes) ${ }^{1,3,4}$, sòmente contando com a memória da sensibilidade proprioceptiva e visual, a qual passa a orientar a ação psicomotora. A atividade motora se exerce sob o contrôle coordenador e regulador extrapiramidal cortical, subcortical e cerebelar, que ajusta o movimento e o torna adequado ao fim desejado.

Quando o paciente executa os kinetogramas êle põe em funcionamento quase todo o sistema nervoso central. A lesão localizada nas vias e centros

* Chefe do Departamento de Neurologia do Hospital Evangélico de Curitiba; Neurologista do IAPFESP em Curitiba, PR. 
nervosos que integram os circuitos internos, mobilizados por ocasião da elaboração kinetográfica, acarreta deformações peculiares no traçado, características do sitio neuromorfofisiológico que lhes deu origem. Constituem-se complexos gráficos resultantes das funçōes nervosas conservadas, suprimidas e modificadas pelo processo mórbido. A observação vem demonstrando que certas enfermidades neurológicas sistematizadas apresentam kinetogramas próprios que se definem desde o início das mesmas, quando outros sintomas e sinais não se manifestam devidamente para caracterizá-las.

Não cabe referir, neste registro de caso, tôdas as vias e centros nervosos utilizados na constituição dos circuitos que integram o mecanismo interno pôsto em funcionamento durante a execução do teste kinetográfico. $\dot{E}$ imprescindível conhecê-los para a interpretação dos traçados e para as correlações anátomo-clínicas.

O teste poderá servir como exame complementar na elucidação do diagnóstico neurológico em casos discutíveis e na fase inicial de enfermidades neurológicas enquanto o quadro clínico não se estabeleceu claramente.

\section{OBSERVAÇAO}

J.W, com 53 anos de idade, sexo feminino, branca, brasileira, examinada em 7-2-1958, apresentando quadro de atetose unilateral à esquerda, possivelmente devido a arteriosclerose agravada por diabete.

Notamos que, quando a paciente realizava os kinetogramas com a mão atetósica os movimentos involuntários, bruscos, arritmicos, hipercinéticos se agravavam (fig. 1). Entretanto, quando ela procurava realizar com as duas mãos simultâneamente (ziguezagues) movimentos simétricos e sinérgicos, diminuia consideràvelmente a irregularidade e extravagância no traçado executado com a mão atetótica (fig. 1). Poder-se-ia dizer que quase se regularizavam, quando comparados com os realizados com a mão atetótica independentemente. Notamos também que os traços feitos com a mão sadia apresentavam tendencia à hipermetria.

Procuremos explicar. Quando a paciente usa na execução kinetográfica sòmente a mão atetótica ( $a$ esquerda), pondo em funcionamento o hemisfério cerebral contralateral doente (o direito), o pallidum em libertação por lesão do striatum responde pela grande irregularidade do traçado. Entretanto, quando a paciente utiliza as duas mãos, em movimentos simultâneos, simétricos e sinérgicos, pondo em funcionamento concomitantemente os dois hemisférios cerebrais, acreditamos que ocorra mecanismo compensador: o striatum do hemisfério sadio exerce ação vicariante sôbre o pallidum do hemisfério doente, através da comissura de Meynert que faz a associação interpalidal bilateral. $O$ influxo prossegue através do fascículo lenticular até o núcleo ventro-lateral anterior do tálamo e finalmente pelo pedúnculo tálamo-cortical chega à área motora do giro central anterior. Assim, o contrôle extrapiramidal poderia chegar a área motora piramidal do hemisfério doente, tendo partido da área cortical extrapiramidal contralateral do hemisfério sadio (áreas supressoras) e realizado um circuito reverberante, aberrante, exercendo suplência. É óbvio que o striatum inte- 

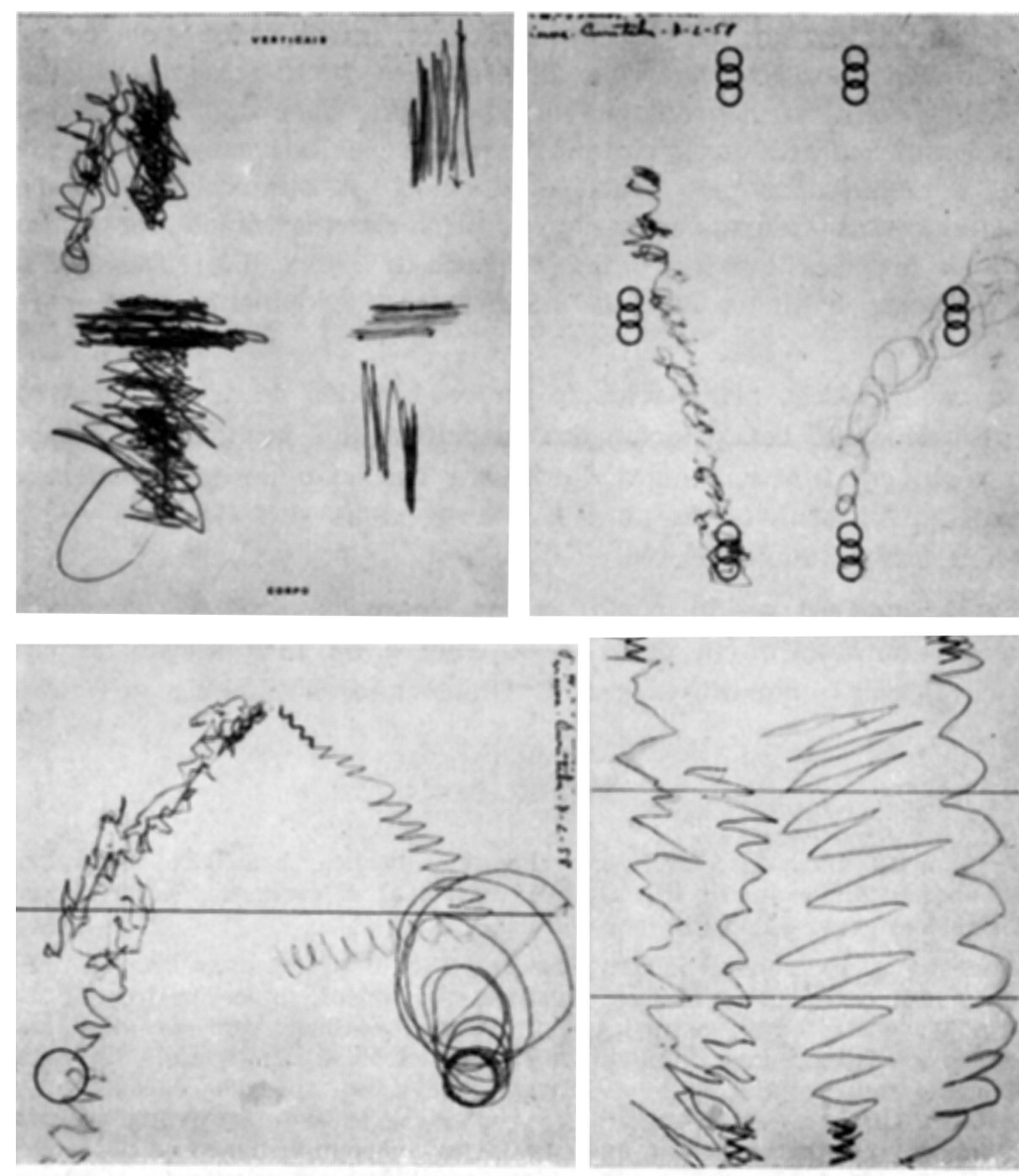

Fig. 1 - Caso J.W. Atetose unilateral à esquerda. Na parte superior, kinetogramas realizados com cada mão isoladamente. Na parte inferior: à sequerda, kinetogramas feitos com cada mão isoladamente; à direita, kinetogramas feitos com as duas mãos simultaneamente, mostrando melhora do traçado feito com a mão atetótica.

gro transmite o contrôle e influxo que recebe do córtex extrapiramidal, além de impor a sua própria função ao pallidum, através das conexões estrio-palidais. Como apenas parte do influxo se difunde para o outro hemisfério, a ação vicariante é parcial. As vias eferentes e descendentes do pallidum conduziriam o contrôle vicariante aos núcleos subjacentes a que se destinam (núcleo rubro, corpo subtalâmico, substância negra, núcleo do fascículo longitudinal medial ou de Darkeschewitsch e da comissura posterior).

Atualmente admite-se que êstes núcleos extrapiramidais mesencefálicos e subtalâmicos possam receber diretamente, através da comissura de Meynert, fibras contralaterais ${ }^{2}$, o que explicaria certa suplência nos casos de 
lesões estrio-palidais unilaterais, que podem ocorrer em certos casos de atetose unilateral. É possivel que outras fibras comissurais inter-hemisféricas, além das que vimos, estabeleçam as conexões bilaterais e conduzam a ação vicariante ou a reforce por ocasião dos movimentos simultâneos, simétricos e sinérgicos das duas mãos. Fibras diretas homolaterais também poderiam conduzir a ação vicariante. A hipermetria evidenciada nos kinetogramas da mão sadia talvez resulte em conseqüência da interferência exercida pelo hemisfério doente sôbre o normal através das comissuras inter-hemisféricas ou então seja acarretada pela descompensação. A paciente não apresentava apraxia ideomotora com a mão esquerda.

\section{RESUMO}

O autor define e explica o que é kinetograma e a técnica de sua realização. Mostra que a movimentação exigida resulta do funcionamento de quase tcdo o sistema nervoso central através de um mecanismo interno complexo do qual participam vários circuitos nervosos. Adverte que as lesões localizadas nestes últimos acarretam deformações e desorganizações kinetográficas peculiares. Informa que a observação vem demonstrando que desde o início de algumas enfermidades sistematizadas do sistema nervoso central existem variações caracteristicas nos traçados.

Em um caso de atetose unilateral, por lesão do striatum contralateral, - autor procura explicar a ação vicariante do hemisfério cerebral homolateral íntegro, por ocasião dos movimentos simultâneos e sinérgicos das duas mãos. Responsabiliza a comissura de Meynert pela condução interpalidal da suplência verificada mediante os kinetogramas e expõe o circuito reverberante aberrante (extrapiramidal) que entra em funcionamento nestas condições excepcionais.

\section{SUMMARY}

\section{Kinetography: interpretation of the kinetograms in a case of unilateral athetosis}

The author explains the kinetogram's technique and says that the necessary movimentation results from a complex mechanism where various nervous circuits participate, emphasizing that lesions located on these circuits produce peculiar kinetographic distortions. He points out that from the beginning of some diseases of the central nervous system there are characteristic changes on the tracings.

In one case of unilateral athetosis the author tries to explain the vicariant action of the normal homolateral cerebral hemisphere during simultaneous movements of both hands. Probably the Meynert's commissure is responsible for the interpallidal conduction of the vicariant control verified through the kinetograms. The reverberating and aberrant circuit which takes action on these conditions is discussed. 


\section{REFERENCIAS}

1. BERNSTEIN, J. - Psicodiagnóstico Miokinético. Fichero de Administración del P.M.K., Ed. Paidos, Buenos Aires, 1962.

2. CROSBY, E. C.; HUMPHREY, T. \& LAUER, E. W. - Correlative Anatomy of the Nervous System. Macmillan Co., New York, 1962, págs. 322-323, 376-378.

3. MIRA Y LOPEZ, E. - Psicodiagnóstico Miokinético. P.M.K., Manual, 2a. Ed. Paidos, Buenos Aires, 1962.

4. MIRA Y LOPEZ, E. - Psicodiagnóstico Miokinético. Ilustraciones del Manual. Ed. Paidos, Buenos Aires, 1962.

Rua Cel. Dulcídio 1383 - Curitiba, PR - Brasil. 